\title{
The ethnographic present revisited
}

I have for a long time been discomforted by the way in which the concept of 'ethnographic present' is being discussed in methodological texts and textbooks in our discipline. In fact, I sense that the concept could be methodologically very useful. I believe that the terms in which it has been discussed have become so stereotyped that they lost any real sense of the actual history of anthropology as it has evolved during the modernist period, in the twentieth century.

As is so often the case with social anthropological discussions about the history of our own practices, we are prone to erect a classical point of reference, somewhere in the early teens of the century - usually the job is done by 'the functionalists'. Then, we proceed to show how mistaken they were. Seldom do we actually discuss in detail the texts we criticise or do we place them in anything like their historical context. At most, we make references to other people that, before us, cast the same criticisms. We know perfectly well what we want to criticise and we function on the presumption (which often proves correct) that the reader will share our sense of indignation. The wall of ignorance concerning the past achievements of anthropology that this produces among our students and younger colleagues is indeed something worth worrying about. I fully share Herbert Lewis' preoccupation with this inheritance of ignorance (1999).

The most outrageous example, to my mind, is the supposed 'colonial stain' of anthropology. However much historians of anthropology demonstrate that people like Radcliffe-Brown, Hoernlé, Schapera or Gluckman were openly anti-segregationists and developed their work with this view in line since the 1920s (cf. Kuper 1999), the supposed 'colonial stain' is taken to cast a deep shadow over the discipline. Readers of our texts are encouraged to believe that 'only recently' did that darker side of anthropology subside.

How can we forget so easily, for example, that Gluckman's whole career was motivated by egalitarian, humanitarian and anti-segregationist considerations? The once famous text on the inauguration of a bridge in 'modern Zululand', that is at the root of much of the methodological practices that have guided us for so long, is more than 60 years old by now (Gluckman 1958 [1st ed. 1940]). We are prone to merge time and place into one common anthropological whole and then proceed to create a phantasmagorical history of the discipline.

For example, in a recent and on the whole most interesting textbook on reflexive ethnography, Charlote Aull Davies argues:

Although most critics agree that anthropological research contributed very little directly to col- 
onial domination, its indirect contribution to the maintenance of the status quo raises fundamental ethical questions about the nature of social research and its exploitative potential, as well as about the viability of a politically neutral position on the part of the researchers (1999: 45).

She follows this immediately by citing the example of the infamous Project Camelot and of the way in which the CIA used anthropology during the Indochina conflicts. Now, there are two very problematic aspects to this. The first is that, in fact, these are not examples of what should properly be considered anthropology in colonial contexts. The deep involvement that anthropology in southern Africa had with fighting the more terrible aspects of the colonial regime - from the 1920s with Radcliffe-Brown and D. D. T. Jabavu to the tragic killing of David Webster in the 1980 s (cf. HammondTooke 1997) - is simply forgotten. The second is that, in order to assure students that anthropology is after all a worthwhile pursuit, we are told that it 'contributed very little directly to colonial domination', and this too is false. For why should we forget the deep involvement of Afrikaans ethnographers and anthropologists in the conception of the apartheid regime? Why should we forget, on the other side of South African's borders, the deep involvement that social scientists from ISCSPU in Lisbon had in the Portuguese colonial administration of Mozambique and Angola?

Very often we write our own methodological history by erecting a-historical and de-contextualised bogeymen that we then proceed to axe down with gusto. This is the very stuff of stereotyping and, I believe, is counterproductive. I have so often heard it said, 'Anthropology is a young discipline'. But what can people possibly mean by this - how do they write their chronologies? My point is that since 'the functionalists' much water has passed under the bridge. We need not feel worried about the aspects in Malinowski's or Evans-Pritchard's works that we disagree with, because many people have been working on them since then, over nearly a century.

Now, let us consider the issue of the 'ethnographic present'. This is how Davies defines it in the book quoted above:

The most common interpretation of the ethnographic present is undoubtedly the practice of developing analyses and generalisations from ethnographic research as if they represent a timeless description of the people being studied. Clearly such an approach implicitly denies the historicity of these people (1999: 156).

I take her point. Everybody takes her point. In fact, what I ask myself is, when did anybody last fail to take that point? (cf. Lewis 1999: 722-3) The question is that history-sensitive ethnography has been practised for very many decades and has become a dominant mode in anthropology ever since the more comparativist excesses of the Lévi-Straussian structuralists went out of fashion in the late 1970s. This being the case, it might be thought that we could lay aside the bogeyman of 'pristine people'/"precontact' ethnography, and start discussing in a more constructive manner the issues raised by the temporal rootedness of all ethnography.

Now the concept of 'ethnographic present' may be used in yet another more literal sense. We could be referring to the practise of writing ethnography in the actual present tense. I do not doubt that this can be used as a tool for de-temporalisation. If and when used in that sense, it is then worthy of being criticised. But it is my contention that we cannot simply rule out the possibility of writing ethnographical descriptions in the present tense. One of the more valuable developments that anthropology has had over the past decades is the discovery that many modes of ethno- 
graphic reporting are legitimately open to us. We can write our ethnographies with much greater rhetorical ingenuity and complexity than we were previously allowed to indulge upon. This, I believe, can only be a positive thing, as it allows for a much more complex interrelation between the material collected, the ethnographer's condition and the theoretical message transmitted.

\section{The ethnographic conjuncture}

Leaving this aside, then, I propose to discuss another sense that the phrase 'ethnographic present' may take and that has struck me as very important in my own experience as an ethnographer (cf. Pina-Cabral 1986; Pina-Cabral and Lourenço 1993). I have discovered that the ethnographies I have written have been rooted in a kind of 'ethnographic present', and that it would have been wrong of mine to have cast that perception aside.

To avoid long discussions and just for the purposes of the present argument, ethnography can be here described as the practice of research that involves the researcher in a person-to-person contact with the object of her study. Whether this is done through some form of 'participant observation' or by any other of the many qualitative methods that have since then been tried out, I believe that it is only useful to call a research ethnographic if the researcher is somehow personally involved in the field.

Now, ever since the early 1980s the majority of anthropologists have taken on board a processualist notion of social life (cf. Ortner 1984) that is not only historicallysensitive, but also sensitive to the more dialogical aspects of the construction of social events (e.g. Comaroff 1985). We have all read, and most of us - friend or foe - have learnt something from works such as Geertz's account of ethnography and cockfighting (1973) or Rabinow's description of his ethnographic efforts in Morocco (1977). This being the case, then, the issue of the historicity - the temporal rootedness - of all ethnographic research is unavoidable.

We do not presume that the sociocultural contexts we study are stopped in time. In fact, we have learnt that there is no means of achieving anything like synchronicity in ethnographic reporting, as sociocultural life is temporally multi-layered (cf. PinaCabral 1987).

The issue takes on yet another angle if we consider that all ethnographic reporting is, explicitly or inexplicitly, based on some form of comparativism. If it is wrong to presume that any sociocultural context could be stable in time, then much worst would it be to presume that any comparison between two or more sociocultural contexts could be stable in time.

Whilst I have openly criticised the notion that ethnography is anything like a 'translation' between western culture and whatever-other culture (cf. Pina-Cabral 1992), I do not deny that some sort of comparative hidden agenda exists in all ethnography. Even although we rarely acknowledge it, all ethnography is written with the spiritual presence of some sort of audience hovering over the shoulders of the ethnographer and metaphorically peeping into the screen of our computers.

Anyone who has written ethnography in two different languages (in my case Portuguese and English) knows perfectly well that it just does not come out in the same way in both languages. In fact, I find that translating my own ethnographic texts is one of the more painful labours of my job and, being lazier in my old age, I avoid it as much as I can. 
Thus, if (a) the presence of the ethnographer is part of the research context; if (b) some sort of comparison is always implicit; and since (c) all comparison between two or more sociocultural contexts is necessarily a matter of conjuncture - and, therefore, time-bound - we must conclude that ethnographers should be very conscious about the chronological articulation of the ethnography they write.

Now, we may be more or less given to emphasising the systematicity of the material we collect. There are fewer and fewer 'structuralists' about these days. But equally there are very few of us who fail to report some sort of systematicity in the material we present to our readers. In fact, it is hard to imagine how one might write an ethnography that fully avoids any sense of the systematicity of sociocultural behaviour. The vaguely metaphysical attributes that characterised some of the treatments of 'the system' in the $1980 \mathrm{~s}^{1}$ have, since then, gone out of fashion. But how many ethnographers today are willing to report that the sociocultural context studied is system free?

The point I aim at is that, if there is some systematicity, then there is some fixity. Now, if sociocultural life is processual, then this fixity is only temporal. But do all things change at the same rate? No. In fact sociocultural life is like a highway where some sociocultural items travel faster than others.

The best example I can find for discussing this point is generations. In an agricultural community, the price of products may well change daily, but do the mindsets of the farmers who sell that produce change daily? Do their identities by relation to major socio-political events that mark ethnic differentiation, for example, change daily? No, as socio-psychologists have been arguing for a while now, people's identifications on the basis of which they build their ego do change through life, but they are primarily formed over time by a set of very early life experiences (cf. Peter Weinreich 1989). Most students of ethnicity have pointed out that ethnic identity is normally acquired as part of one's primary solidarities (cf. Pina-Cabral 1994). ${ }^{2}$

To sum up so far: (a) the people the ethnographer knows and speaks to belong to specific generations; (b) they are involved in social, cultural, economic and political contexts that have some durability; (c) they are related to the other sociocultural contexts that the ethnographer implicitly takes as points of comparison in modes that change over time. Therefore, the conjuncture of the ethnographic research is part of what is being reported in unavoidable ways.

\section{Timed contexts of research: a peasant society vanishes}

I will now briefly outline two situations in which I have found myself, that can be taken as examples of what I have in mind. My first fieldwork experience was carried out in the Alto Minho (north-western Portugal) in the late 1970s and early 1980s among the inhabitants of two rural parishes (cf. Pina-Cabral 1986). To avoid lengthy discussions, which would be misplaced in terms of the present argument, I will summarily characterise the situation. I found there a rural population that lived in a long-

1 For critical identification of the problem, cf. Ortner 1984; for examples, aside from the usual Bourdieu references, see Comaroff's brilliant ethnography of the Tshidi (Tswana, South Africa), 1985.

2 Cf. Carmelo Lisón-Tolosana's classical discussion of this issue by relation to the Spanish Civil War that, to my mind, remains one of the most valuable ones to date (cf. 1966). 
term historical relation to dominant urban-based cultures and political structures, but nevertheless preserved some elements of socio-cultural autarky (cf. Pina-Cabral 1987). I decided that I could characterise it aptly by calling it a 'peasant community' following on a prestigious line of studies of such populations. I identified a 'peasant worldview' with marked elements of systematicity and historical continuity.

In fact, the society I studied had been deeply marked by rural poverty throughout the end of the nineteenth and the first half of the twentieth centuries. In the 1960s, as a response to increased demands in labour in the fast growing economies of France, Germany, Switzerland, the United States, Canada, South Africa and Australia, the men of these rural areas emigrated in hoards - heroically escaping the vain attempts of Salazar's police to keep them tied down to their condition as cheap rural labour. When I arrived there, in the late 1970s, the flood had stopped. In fact, many older migrants were returning to re-invest locally their earnings, build their new houses, and buy back the land their parents had lost to creditors. There was an increased sense of prosperity and I witnessed the beginning of their integration into a globalised culture of consumption: I helped installing some of the first television sets and explaining the basic meaning of many of the programs; I saw electrical power and paved roads arriving at the hamlets that were higher up in the hills (cf. Pina-Cabral 1987); I helped to explain how one consumed prefabricated yoghurt and what was the use of cornflakes; I explained what medicines to take by self-prescription and what others to ask the doctor; I explained the ins and outs of a bank account; and I carted about many people in my car that still did not have one.

By the mid 1980s, however, all this had quickly changed. Portugal had entered the European Union and infrastructures were improving at a heady pace especially important were the improvements in communications. Migrants were now in their second generation - the ones that had not lost their local links, had assumed a kind of multinational citizenship, as they were no longer a dispossessed proletariat in France or Germany or an impoverished peasantry in Portugal. The change in fertility patterns had taken place and family planning and contraception were a fundamental part of life. Schooling was improving and had become nearly universal. People's entry into the world of global consumption - both in goods and in cultural items - had been largely accomplished. The older informants that had spent so much of their time with me, studying the old customs and old methods that they so cherished, started to die. It became clear to me that this was no longer a 'peasant community'. They had assumed a kind of peri-urban condition that meant that I would have to change completely the way I was describing them.

In fact, I became aware that my short visits to the field to speak to older people and my use of my own field-notes as archival sources were becoming increasingly anachronistic. I was pushing on to the present, the experiences that I had lived in a sort of past. The issue that most preoccupied me, I think, was the deep sense of evidence that the experiences I was describing had for me. I mean, I had not only read that peasants buried their unbaptised children beneath their hearth or secretly at night in an unmarked spot in the cemetery (to give one such example). I had had lengthy, heartto-heart discussions with a man that had done it, and that had felt it as one of the saddest moments of his life. I had discussed at length with a woman who believed her friend, whose labour she was assisting, had given birth to a kind of salamander. I had known more than one woman who had been forced to sell sexual services to a neigh- 
bour in order to feed herself during the winter. After becoming pregnant, they had to work to the last hour throughout their summer's pregnancies, giving birth to their fatherless children alone, behind some bushes, in the fields where they had been working.

But the new generation, what did they know of all this? People were being born and dying in hospitals. There were no more 'illegitimate mothers' - the women who got pregnant out of wedlock either got married, aborted or, in the few cases where they had decided to keep the child, moved to urban contexts where the stigma was less biting.

I have purposefully chosen graphic examples of situations to do with the human body that most of us humans can understand in a direct sort of fashion. But the issue of the growing anachronism of my research troubled me more widely. The associations that I had built between economic, political and cultural factors - between identities and material conditions - and on the basis of which my ethnography had acquired texture, systematicity and interest, these associations were slipping away right before my very eyes. So I decided to stop. I decided that my ethnography had an 'ethnographic present' and was not dissociable from it, however much I infused my writings with history; however much I used the past tense; however much I phrased what I was doing by the late 1980 s as 'a re-study'.

I am, therefore, weary of so called 'longitudinal studies' that do not directly address the issue of conjuncture in the ethnographic research experience and the ensuing description. In fact, Charlotte Aull Davies gives just such an example of the sort of problems that concern me:

a longitudinal study designed to look at coping strategies for dealing with old age or debilitating accident or illness which spanned years in which a major system of state welfare benefits were introduced would face a significant discontinuity in the external conditions affecting such coping strategies and would have to ask a very different set of questions in a return study (1999: 175).

\section{Timed contexts of research: an elite loses its privilege}

It might be said that the problems I faced in the Alto Minho were due to specific contextual changes. But are not all ethnographic situations equally 'specific'? Perhaps my experience is unique, but I have started to doubt it since I find myself at present in a very similar quandary concerning the fieldwork I carried out in the 1990s among the Eurasian administrative elite of Macao (cf. Pina-Cabral and Lourenço 1993; PinaCabral 2000).

In short, the people I studied there were the Eurasian descendants of a four-centuries' long tradition of contacts between Portuguese merchants, military officers and administrators and the Chinese lower classes of the Canton region. Macao's wealthy merchants - aside from the first few decades of the city's history in the sixteenth century - were always Chinese Cantonese speakers who seldom mixed their offspring with Europeans or took on European wives. Macao's governors and bishops were always Portuguese and seldom left descendants in the city. The Eurasians fulfilled a central role as intermediaries and low level administrators, using those posts as an ethnic privilege that protected them from the utter poverty that characterised the mass of the Chinese people over the nineteenth and most of the twentieth centuries. After 
the foundation of Hong Kong in the 1840s and up to the late 1950s, they played the same role in that British colony.

The 1960s and 1970s, however, saw a major change in the balance of ethnic relations in both cities with the rise of an ethnically Chinese middle-class. The 1980s were a period of immense economic growth and, although the Eurasians had practically lost their foothold on Hong Kong, they managed to preserve and, in fact, reconstruct it in Macao. But, by the early 1990s, it was known that Macao would be handed over to China in 1999 and that this would change the local ethnic equilibrium. The funds for my research, in fact, resulted from a call for anthropological work that originated in Macao's administration and was supported by the most eminent local Eurasians. The need was felt to do a study of what was happening in the city's ethnic composition.

Cutting short much of what could be said, the point of all this for the present argument is that 1999 came, and Macao was handed over to China, and the Eurasians who stayed behind are undergoing the fully predictable process of ethnic re-contextualization. Does it make sense to continue research as if this process had not occurred? But more than that: should one continue the very same line of enquiry as was done in the first part of the 1990s, or should one start anew? If the later solution was felt to be the best, we must then ask ourselves: to what extent can an ethnographer extricate him or herself from the earlier identifications, friendships and collaborations that made fieldwork possible? Can he or she do a plain re-study without at least a considerable period of distancing? Is his or her ethnography not marked by an ethnographic present?

My response is that, whatever a researcher opts to do when faced with challenges such as these (and there is never one single solution to such complicated questions), the conscious formulation of the existence of an ethnographic conjuncture should become accepted practice in anthropology. I think that, instead of continuing to be frightened by the 'functionalist' bogeyman, we could usefully apply the phrase 'ethnographic present' to speak of that awareness of the conjunctural nature of all ethnography.

João de Pina-Cabral

Institute of Social Sciences

University of Lisbon

Av. Forcas Armadas, Edif. ISCTE

1600 Lisbon

Portugal

\section{References}

Comaroff, Jean. 1985. Body of power, spirit of resistence. The culture and history of a South African people. Chicago: University of Chicago Press.

Davies, Charlotte Aull. 1999. Reflexive ethnography. A guide to researching selves and others. London: Routledge.

Geertz, C. 1973. 'Deep play. Notes on the Balinese cockfight' in C. Geertz, The interpretation of cultures. New York: Basic Books.

Gluckman, Max. 1958 [1940]. An analysis of a social situation in modern Zululand. RhodesLivingstone Paper no. 14. Manchester: Manchester University Press.

Hammond-Tooke, W. D. 1997. Imperfect interpreters: South Africa's social anthropologists. Johannesburg: Witwatersrand University Press. 
Kuper, Adam. 1999. 'South African anthropology: an inside job' in Adam Kuper, Among the anthropologists. History and context in anthropology: 145-170. London: Athlone.

Lewis, Herbert S. 1999. 'The misrepresentation of anthropology and its consequences', American Anthropologist 100: 716-31.

Lisón-Tolosana, Carmelo. 1966. Belmonte de los Caballeros. Oxford: Oxford University Press (2nd ed, 1983: Princeton University Press).

Ortner, Sherry. 1984. 'Theory in anthropology since the sixties', Comparative Studies in Society and History 26: 126-66.

Pina-Cabral, João de. 1986. Sons of Adam. Daughters of Eve. The peasant worldview of the Alto Minho. Oxford: Clarendon Press.

1987. 'Paved roads and enchanted mooresses. The valuation of time among the peasant population of the Alto Minho, NW Portugal)', Man 22: 715-35.

1992. 'Against translation. The role of the researcher in the production of ethnographic knowledge', in João de Pina-Cabral and John Campbell (eds.) Europe observed: 1-23. London: Macmillan.

1994. 'Personal identity and ethnic ambiguity. Naming practices among the Eurasians of Macau', Social Anthropology 2: 115-32.

1998. 'Traffic humain à Macao. Les compatibilités équivoques de la communication interculturelle', Ethnologie Française 29: 225-36.

1999a. 'A composição social de Macau', in Francisco Bettencourt and K. Chaudhuri (eds.), História da Expansão Portuguesa V: 275-301. Lisbon: Círculo de Leitores.

1999b. 'The threshold diffused. Margins, contraditions and hegemonies in contemporary anthropology', in Patrick MacAllister (ed.), Culture and the commonplace. Anthropological essays in honour of W. D. Hammond-Tooke. Johannesburg: Witwatersrand University Press.

2000. 'How do the Macanese achieve collective action?', in João de Pina-Cabral and Antónia Pedroso de Lima (eds.), Elites. Choice, leadership and succession: 201-25. Oxford: Berg.

Pina-Cabral, João de, and Mónica Chan. 1998. 'O parasita do mandarim. A lotaria dos exames imperiais (vaeseng) em Macau e Cantão’, Oceanos 32: 151-63.

Pina-Cabral, João de, and Nelson Lourenço. 1993. Em terra de Tufões. Dinâmicas da etnicidade Macaense. Macau: Instituto Cultural de Macau.

1993b. 'Macau Bambu - um estudo sobre a identidade étnica macaense e a sucessão de gerações', Administração 21: 523-58.

Rabinow, P. 1977. Reflections on fieldwork in Morocco. Berkeley: University of California Press.

Weinreich, Peter. 1989. 'Variations in ethnic identity. Identity structure analysis', in karmela liebkind (ed.), New identities in Europe. Vermont: Gower. 